\title{
Contaminação de águas superficiais e de chuva por agrotóxicos em uma região do estado do Mato Grosso
}

\author{
Groundwater and rainwater contamination by pesticides \\ in an agricultural Region of Mato Grosso State in Central Brazil
}

Josino Costa Moreira ${ }^{1}$

Frederico Peres ${ }^{1}$

Ana Cristina Simões ${ }^{1}$

Wanderlei Antonio Pignati ${ }^{2}$

Eliane de Carvalho Dores ${ }^{2}$

Sandro Nunes Vieira ${ }^{2}$

Christine Strüssmann ${ }^{2}$

Tamí Mott ${ }^{3}$

${ }^{1}$ Centro de Estudos da Saúde do Trabalhador e Ecologia Humana, Escola Nacional de Saúde Pública Sergio Arouca, Fundação Oswaldo Cruz. Rua Leopoldo Bulhões 1480,

Manguinhos. 21041-210

Rio de Janeiro RJ.

josinocm@fiocruz.br

${ }^{2}$ Departamento de Saúde

Coletiva, Pró-Reitoria de

Ensino e Graduação,

Universidade Federal do

Mato Grosso.

${ }^{3}$ Instituto de Ciências

Biológicas e da Saúde,

Universidade Federal de

Alagoas.
Abstract This study sought to analyze groundwater and rainwater contamination by pesticides in two municipalities (Lucas do Rio Verde and Campo Verde) of Mato Grosso state. The area is Brazil's mid-west situated among the major soybean, corn and cotton producers in the state and the country. The analytical methodology combined chromatographic techniques on groundwater and rainwater samples with eco-toxicological analyses of the impacts of contamination by pesticide on bio-indicator species. The results revealed the presence of different pesticide residues in the groundwater and rainwater samples collected in the two municipalities. In conjunction with this data, results of the eco-toxicological tests revealed the presence of anomalies in a bio-indicator species collected in one of the two study sites compatible with exposure to pesticides. The results presented and discussed here highlight the degradation of water resources in the region, caused by the intensive use of pesticides in agriculture, including the contamination of drinking water sources and rain, broadening the risk of contamination beyond the cultivated areas.

Key words Pesticides, Environmental pollution, Groundwater, Bio-indicator species, Environmental health
Resumo O presente trabalho objetivou analisar a contaminação de águas superficiais e de chuvas por agrotóxicos em dois municípios do estado do Mato Grosso, Lucas do Rio Verde e Campo Verde, situados entre os maiores produtores de soja, mitho e algodão do estado e do país. A metodologia analitica combinou o uso de técnicas cromatográficas em amostras de água superficial e de chuva com análises ecotoxicológicas do impacto da contaminação por agrotóxicos sobre espécies bioindicadoras. Resultados das análises mostraram a presença de resíduos de diferentes agrotóxicos nas amostras de águas superficiais e de chuva coletadas nos dois municípios. Associados a estes dados, resultados das análises ecotoxicológicas mostraram a presença de anomalias em uma espécie de anfíbio anuro coletado em uma das duas localidades, compatíveis com exposição a agrotóxicos. Os resultados aqui apresentados e discutidos apontam para a degradação da qualidade de recursos hídricos da região, causada pelo uso intensivo de agrotóxicos na agricultura, incluindo fontes de água de consumo humano e de chuvas, amplificando o risco de contaminação para além das áreas de plantio.

Palavras-chave Agrotóxicos, Contaminação ambiental, Águas superficiais, Espécies bioindicadoras, Saúde ambiental 


\section{Introdução}

O agronegócio é, hoje, uma das principais atividades econômicas nacionais. Estimativas mostram que contribui com cerca de $30 \%$ do PIB, o que significa a geração de aproximadamente de 350 bilhões de dólares anualmente. Adicionalmente, responde por cerca de um terço das exportações nacionais'.

Entre 2000 e 2009, o valor obtido com exportações brasileiras ligadas ao agronegócio cresceu aproximadamente $300 \%$, de US $\$ 20,6$ bilhões em 2000 para US\$ 69,4 bilhões em $2009^{1}$. Uma importante parcela desse montante pode ser atribuída ao estado do Mato Grosso, maior produtor nacional de grãos e outras commodities agrícolas que, somadas, se apresentam como força motrizes do saldo positivo da balança comercial nacional ${ }^{2}$.

Dados da Companhia Nacional de Abastecimento $^{3}$ (Conab) mostram que de um total de 162,05 milhões de toneladas de grãos produzido na safra 2010/11, o estado do Mato Grosso foi responsável por cerca de 19\%, num volume aproximado de 55,7 milhões de toneladas. Esta produção foi obtida a partir de uma área cultivada de 9,59 milhões de hectares e representou 27,65\% da soja, $51,12 \%$ do algodão e $5,83 \%$ do milho produzidos neste país ${ }^{3}$.

A produção de grandes monoculturas de exportação, como a soja, o milho e o algodão, no estado do Mato Grosso tem sido associada a um intensivo uso de agrotóxicos ${ }^{2}$. No caso da soja, o principal utilizado é o herbicida glifosato, usado principalmente no controle de pragas vegetais em lavouras geneticamente modificadas, seguido do metamidofós, endosulfan (inseticidas), 2,4D (herbicida), tebocunazol (fungicida) e atrazina (herbicida) ${ }^{4,5}$. A Agência Nacional de Vigilância Sanitária (Anvisa) determinou, recentemente, que dois desses seis agrotóxicos (metamidofós e endosulfan) ${ }^{6,7}$ sejam retirados do mercado brasileiro em função de seu potencial tóxico para a saúde humana.

O potencial de contaminação ambiental e humana pelos agrotóxicos usados na produção de grãos e algodão no estado do Mato Grosso, bem como seus impactos sobre a biota, é presumível, embora não se tenham estudos mais aprofundados que caracterizem esse impacto. O presente trabalho objetiva contribuir para o conhecimento mais concreto desse problema de saúde ambiental, através da análise da contaminação de águas superficiais e de chuva por agrotóxicos nos municípios de Lucas do Rio Verde e Campo Verde, dois dos mais importantes municípios produtores de soja, milho e algodão do estado, assim como analisar os possíveis impactos dessa contaminação ambiental em espécies bioindicadoras (anfíbios anuros) que habitam córregos e lagoas adjacentes às áreas de produção agrícola desses municípios.

\section{Metodologia}

Para a realização deste trabalho foram selecionadas as cidades de Lucas do Rio Verde e Campo Verde, estado do Mato Grosso, por se situarem entre as maiores produtoras de milho, soja e algodão do estado.

Lucas do Rio Verde (latitude 130.'01" sul e longitude $55^{\circ} 54^{\prime} 40^{\prime \prime}$ oeste) é uma cidade com cerca de 25 anos e com uma população estimada em 45.545 habitantes. Ocupa o terceiro lugar no ranking dos melhores Índices de Desenvolvimento Humano (IDH) do Estado ${ }^{8}$. A produção de grãos é a maior fonte de renda do município que, agora, conta ainda com agroindústrias de beneficiamento de avícolas, suínos e grãos?

Campo Verde (latitude 1532'48" sul e longitude $55^{\circ} 10^{\prime} 08^{\prime \prime}$ oeste) tem uma população de 31.612 habitantes e também possui um elevado IDH sendo o maior produtor de algodão do Brasil, com uma área plantada superior a 70 mil hectares e uma produção superior a 200.000 toneladas $/ \mathrm{ano}^{10}$.

\section{Coleta de Dados}

\section{Dados referentes ao uso de agrotóxicos nos municípios}

O levantamento dos principais agrotóxicos utilizados na região estudada foi feito através da análise de dois bancos de dados do Instituto de Desenvolvimento Agropecuário do Mato Gros$\mathrm{so}^{4,5}$ (Indea), baseados no registros de informações contidas em receituários agronômicos relativos ao período de 2005 a 2009. De fato, a partir de janeiro de 2005, o Indea instituiu um Sistema de Informação de Agrotóxicos, organizado através das notas fiscais e de dados retirados dos receituários agronômicos. Através de solicitação ao Indea, obteve-se dois bancos de dados eletrônicos (planilhas em CD) desse Sistema de Informação, um em março de $2008^{4}$, com dados de 2005 a 2007 e outro em fevereiro de 2010 com dados de 2008 e $2009^{5}$. 
Amostras de água superficiais e de chuva

Com base na análise dos bancos de dados do Indea ${ }^{4,5}$, foram selecionados 27 princípios ativos, entre os herbicidas, os inseticidas e os fungicidas mais utilizados nas lavouras nos anos de 2006 e 2007. Os pontos de coletas, nos dois municípios, incluíram: poços artesianos (20) em propriedades próximas às áreas de plantio e no centro das duas cidades; e dois córregos (6 pontos em cada) e dois rios (6 pontos em cada) das áreas rurais de cada um dos dois municípios. As amostras foram coletadas bimensalmente durante $18 \mathrm{me}$ ses, entre 2007 e 2009. As águas dos poços foram coletadas diretamente na saída da bomba de cada poço, com descarte das amostras obtidas nos primeiros 3 minutos. O volume coletado foi colocado em três garrafas de vidro âmbar de $1 \mathrm{~L}$. Para coleta de amostras de água de água de rios e córregos, foram utilizadas 3 garrafas de $1 \mathrm{~L}$ de vidro âmbar, imersas em uma profundidade de $30 \mathrm{~cm}$ (quando possível) dos pontos pré-determinados no córrego e rio.

Coletores de chuva foram instalados em unidades escolares localizadas geograficamente em diferentes pontos dos dois municípios sendo coletadas 104 amostras em Lucas do Rio Verde e 58 em Campo Verde.

As amostras foram mantidas refrigeradas $\left(4^{\circ} \mathrm{C}\right)$ até o momento da extração.

\section{Coleta de espécies bioindicadoras}

A coleta de espécies de anfíbios anuros (bioindicadores da contaminação ambiental por agrotóxicos) para as análises ecotoxicológicas foi feita em dois córregos do município de Lucas do Rio Verde. Dentre as 16 espécies de anfíbios anuros encontradas nesses dois córregos, duas foram selecionadas por serem abundantes e de grande tamanho: o sapo-cururu ou sapo-leiteiro (Rhinella schneideri) e a rã-pimenta ou gia (Leptodactylus labyrinthicus). As coletas restringiram-se a esses dois córregos, nos quais já vinha sendo detectada a presença de agrotóxicos na água e sedimentos. No córrego Cedro, localizado na comunidade rural de São Cristovão, a $30 \mathrm{~km}$ de Lucas do Rio Verde, a mata ciliar é mais larga e menos alterada do que no córrego do Xixi, situado nas proximidades da zona urbana de Lucas do Rio Verde e cuja nascente foi barrada para o estabelecimento de uma represa. As coletas foram realizadas nos meses de novembro de 2008, março e setembro de 2009 e julho de 2010.

\section{Análise dos Dados}

Análise dos bancos de dados

sobre uso de agrotóxicos

Os dados fornecidos pelo Indea nas duas ocasiões descritas foram tabulados em um único banco de dados do Excel (Microsoft Corporation). Para as análises de padrão de consumo e evolução, foram utilizadas ferramentas estatísticas desse software.

Análise das amostras de águas superficiais e de chuva

As amostras de água, foram coletadas e analisadas por cromatografia a gás acoplada com detector de massas (CG/EM) após extração em fase sólida C-18. Os resíduos de agrotóxicos presentes foram analisados de acordo com procedimento validado anteriormente pelo Departamento de Química da UFMT ${ }^{11}$.

\section{Análises ecotoxicológicas}

Trinta e seis indivíduos (14 sapos da espécie Rhinella schneideri, Bufonidae, e 22 rãs da espécie Leptodactylus labyrinthicus, Leptodactylidae) de anfíbios anuros coletados nos dois córregos de Lucas do Rio Verde foram sedados e amostras de sangue foram obtidas por meio de cardiocentese no Laboratório de Herpetologia da UFMT. As amostras de plasma foram congeladas e enviadas ao Centro de Estudos da Saúde do Trabalhador e Ecologia Humana, Fundação Osvaldo Cruz, RJ para serem analisadas por extração em fase sólida e cromatografia em fase gasosa, através de método validado para 28 organoclorados.

\section{Aspectos éticos da pesquisa}

$O$ presente trabalho obedeceu às normas da Resolução 196/96 do Conselho Nacional de Saúde, tendo sido submetido, analisado e aprovado pelo Comitê de Ética em Pesquisa da Escola Nacional de Saúde Pública Sergio Arouca. A coleta e as análises ecotoxicológicas de espécies bioindicadoras foram aprovadas pela Comissão de Ética em Experimentação Animal da Universidade Federal de Mato Grosso.

\section{Resultados}

A Tabela 1 sumariza informações acerca dos agrotóxicos mais utilizados em Lucas do Rio Verde e em Campo Verde, bem como suas classificações 
toxicológica e de risco ambiental. Observa-se um elevado consumo desses agentes químicos, em particular de herbicidas e fungicidas. Também é possível observar que ainda há um grande consumo de agrotóxicos já proibidos na Europa e nos Estados Unidos, como o endosulfan e o metamidofós que, só recentemente, começam a ser gradativamente retirados do mercado brasileiro, por determinação da Anvisa ${ }^{6,7}$. Outros, como o paration metílico, também detectado, ainda têm uso permito no país.

Com relação à área plantada, podemos observar padrões distintos de culturas e utilização de terras agriculturáveis nesses dois municípios (Tabela 2).

O consumo de agrotóxicos em Lucas do Rio Verde aumentou aproximadamente $70 \%$, variando de 3,65 milhões de litros em 2005 para 5,16 milhões em $2009^{5}$. A análise desse banco de dados nos permitiu observar que o consumo de agrotóxicos Extremamente Tóxicos caiu em aproximadamente $29 \%$; já o consumo de agrotóxicos classificados como Altamente Tóxicos e Pouco Tóxicos cresceu, respectivamente, $41 \%$ e $60 \%$ (este último influenciado pelo aumento no consumo do herbicida glifosato, decorrente ao crescimento do percentual de soja geneticamente modificada plantada no município).

No município de Lucas do Rio Verde, os herbicidas representaram $60 \%$ de todos os agrotóxicos utilizados, seguido dos inseticidas (13\%) e fungicidas (9\%).

O consumo de agrotóxicos em Campo Verde aumentou aproximadamente $20 \%$, variando de 4,15 milhões de litros em 2005 para 4,92 milhões em $2009^{5}$. Nesse período, o uso de agrotó-

Tabela 1. Consumo médio anual dos agrotóxicos mais vendidos em Lucas do Rio Verde e em Campo Verde, MT entre 2005 e 2009.

\begin{tabular}{|c|c|c|c|c|}
\hline Agrotóxico & $\begin{array}{l}\text { Lucas do } \\
\text { Rio Verde }\end{array}$ & $\begin{array}{c}\text { Campo } \\
\text { Verde }\end{array}$ & $\begin{array}{c}\text { Classe } \\
\text { toxicológica }\end{array}$ & $\begin{array}{l}\text { Classificação } \\
\text { risco ambiental }\end{array}$ \\
\hline Glifosato & 1.261 .957 & 695.296 & III e IV & III \\
\hline Atrazina & 390.061 & 150.708 & III & III \\
\hline Metamidofós & 381.438 & 289.363 & I & II \\
\hline Endosulfan & 216.950 & 342.697 & I & I \\
\hline Paraquat + diquat & 167.219 & 107.328 & I & II \\
\hline $2,4 \mathrm{D}$ & 184.970 & 203.819 & I & III \\
\hline S-Metolacloro & 87.120 & 90.938 & I & II \\
\hline Metil paration & 77.497 & 106.037 & I & III \\
\hline Acefato & 73.280 & 22.594 & II & III \\
\hline Clorpirifós & 47.145 & 65.196 & I & I \\
\hline Triflurallina & 23.094 & 66.293 & II & II \\
\hline Permetrina & 22.985 & 9.131 & III & II \\
\hline Cipermetrina & 19.636 & 76.519 & III & II \\
\hline Malation & 11.911 & 23.800 & III & III \\
\hline MSMA & 9.860 & 6.480 & III & III \\
\hline Fipronil & 8.047 & 200 & II & II \\
\hline Monocrotofós * & 4.792 & 3.174 & I & I \\
\hline Carbofuran & 3.981 & 4.594 & I & II \\
\hline Deltametrina & 1.179 & 2.255 & IV & I e II \\
\hline Tebuconazol & 41.734 & 220.633 & III & II \\
\hline Metomil & 188.833 & 205.073 & I & II \\
\hline Clomazona & 26.100 & 164.980 & II & II \\
\hline Carbosulfan & 19.966 & 153.517 & II & II \\
\hline Carbendazin & 95.407 & 95.935 & II & III \\
\hline Etefon & 12.616 & 80.533 & II & II \\
\hline Fenoxaprop-P-metil + cletodim & 29.941 & 80.002 & II & II e III \\
\hline Flutriafol & 4.867 & 77.410 & II & III \\
\hline Diuron & 14.727 & 73.408 & III & II \\
\hline Sub total & 3.427 .313 & 3.417 .913 & & \\
\hline Outros & 902.173 & 1.178 .805 & & \\
\hline Total & 4.329 .486 & 4.596 .718 & & \\
\hline
\end{tabular}

Fonte: INDEA ${ }^{4,5}$. 
xicos Extremamente Tóxicos diminuiu em aproximadamente $31 \%$ enquanto o de agrotóxicos classificados como Altamente Tóxicos e Pouco Tóxicos cresceu cerca de 30\% (Tabela 1). Aqueles considerados medianamente tóxicos tiveram seu consumo aumentado em $100 \%$ mostrando a influência do uso de inseticidas decorrente da maior área plantada de algodão em comparação com o município de Lucas do Rio Verde (Tabela 2). De fato, neste município, o consumo de inseticidas representou $46 \%$ do consumo total, seguido pelos herbicidas (38\%) e fungicidas (16\%).

\section{Resultados das análises de amostras de águas superficiais e de chuva}

Nas Tabelas 3 e 4 encontram-se os resultados das análises dos resíduos dos agrotóxicos estudados que foram identificados e, eventualmente quantificados, nas amostras de água superficiais, de poços artesianos e de chuvas coletadas nas cidades de Lucas do Rio Verde e Campo Verde no período abrangido por este estudo.

Em Lucas do Rio Verde, foram coletadas e analisadas 62 amostras de aguas de poços artesianos e resíduos dos agrotóxicos atrazina, metolacloro, clorpirifós, endosulfan alfa e beta, flutriafol e permetrina foram detectados em várias amostras de águas dos poços artesianos, utilizadas na distribuição urbana. As maiores prevalências foram das substâncias endosulfan alfa e beta, flutriafol e metolacloro. A presença de resíduos de agrotóxicos foi identificada em $83 \%$ das amostras analisadas, incluindo vários poços que abastecem várias escolas.
Em Campo Verde, cerca de 50\% das 28 amostras de água de poços coletadas apresentaram resíduos dos agrotóxicos identificados nas amostras de águas em concentrações que variaram de 0,18 $\mu \mathrm{g} / \mathrm{L}$ a $18,96 \mu \mathrm{g} / \mathrm{L}$. Estes valores foram confrontados com aqueles recomendados pelas legislações brasileira e de alguns países, para água potável.

No Brasil, a Portaria MS 2.914 ${ }^{12}$, que segue as recomendações da OMS, estabelece como padrão de potabilidade de água para a atrazina, o valor de $2 \mu \mathrm{g} / \mathrm{L}$, para o endosulfan (alfa, beta e sais) 20 $\mu \mathrm{g} / \mathrm{L}$, para o metolacloro $10 \mu \mathrm{g}$.L e para o clorpirifós (+clorpirifós oxon) $30 \mu \mathrm{g} / \mathrm{L}$. Essa Portaria, entretanto, não estabelece limites para o flutriafol nem para a cipermetrina.

Com relação à água de córregos e rios, em Lucas do Rio Verde, foram coletadas 34 amostras provenientes de 8 pontos em 4 rios. Deste universo amostral, foram encontrados resíduos de pelo menos um dos agrotóxicos avaliados em $81 \%$ das amostras. Os resíduos mais frequentemente encontrados foram os de endosulfan, flutriafol e metolacloro que em várias amostras apareceram conjuntamente.

Em Campo Verde, foram analisadas 16 amostras de água de córregos e rios coletadas entre novembro de 2007 e maio de 2008 em quatro pontos do município. Os resultados obtidos identificaram a presença de atrazina e seu produto de degradação DEA e endosulfan alfa e beta em concentrações que variaram até $0,25 \mu \mathrm{g} / \mathrm{L}$. Nestas amostras foram identificados resíduos de atrazina, um de seus produtos de degradação (DEA), endosulfan alfa, beta e sulfato), clorpirifós, flutriafol, malation metolacloro e permetrina.

Tabela 2. Área plantada de algodão, milho e soja (hectares) no Estado do Mato Grosso e nos municípios de Lucas do Rio Verde e Campo Verde entre 2005 e 2009

\begin{tabular}{|c|c|c|c|c|c|c|c|}
\hline & \multirow[b]{2}{*}{ Lavoura } & \multicolumn{5}{|c|}{ Ano } & \multirow[b]{2}{*}{ Média } \\
\hline & & 2005 & 2006 & 2007 & 2008 & 2009 & \\
\hline Mato Grosso & Milho & 1.073 .146 & 1.079 .980 & 1.650 .471 & 1.832 .687 & 1.665 .470 & 1.460 .351 \\
\hline Mato Grosso & Soja & 6.121 .724 & 5.822 .867 & 5.075 .079 & 5.659 .149 & 5.831 .468 & 5.702 .057 \\
\hline Mato Grosso & Algodão herbáceo & 483.525 & 392.408 & 560.838 & 539.586 & 357.543 & 466.780 \\
\hline Total MT & & & & & & & 7.629 .188 \\
\hline Campo Verde & Milho & 58.515 & 63.820 & 68.986 & 70.498 & 63.360 & 65.036 \\
\hline Campo Verde & Soja & 161.206 & 147.200 & 120.000 & 126.000 & 145.000 & 139.881 \\
\hline Campo Verde & Algodão herbáceo & 62.580 & 57.613 & 73.623 & 67.360 & 47.520 & 61.739 \\
\hline Total CV & & & & & & & 266.656 \\
\hline Lucas do Rio Verde & Milho & 146.248 & 147.057 & 175.073 & 160.480 & 138.000 & 153.372 \\
\hline Lucas do Rio Verde & Soja & 221.906 & 224.420 & 215.535 & 225.830 & 223.500 & 222.238 \\
\hline Lucas do Rio Verde & Algodão herbáceo & 9.765 & 7.102 & 15.015 & 11.050 & 4.980 & 9.582 \\
\hline Total LRV & & & & & & & 385.192 \\
\hline
\end{tabular}

Fonte: $\mathrm{MAPA}^{2} ; \mathrm{INDEA}^{4,5}$. 
Tabela 3. Resultados das Análises de resíduos de agrotóxicos em águas superficiais, de poços artesianos (potável) e de chuva em Lucas do Rio Verde, MT; amostras coletadas entre set.2007 a abr.2009

\begin{tabular}{|c|c|c|c|c|c|c|}
\hline \multirow[b]{2}{*}{ Agrotóxicos } & \multicolumn{2}{|c|}{ Água Superficial } & \multicolumn{2}{|c|}{ Poços artes. (potável) } & \multicolumn{2}{|c|}{ Água de chuva } \\
\hline & $\begin{array}{c}(\mathrm{N}=34) \\
\text { Amostras } \\
\text { Positivas }\end{array}$ & $\begin{array}{c}\text { Concentração } \\
(\mu \mathrm{g} / \mathrm{L})\end{array}$ & $\begin{array}{c}(\mathrm{N}=62) \\
\text { Amostras } \\
\text { Positivas }\end{array}$ & $\begin{array}{l}\text { Intervalo } \\
\text { em } \mu \mathrm{g} / \mathrm{L}\end{array}$ & $\begin{array}{c}(\mathrm{N}=104) \\
\text { Amostras } \\
\text { Positivas }\end{array}$ & $\begin{array}{c}\text { concentração } \\
(\mu \mathrm{g} / \mathrm{L})\end{array}$ \\
\hline Atrazina & 3 & $0,02-4,92$ & 2 & $0,01-0,02$ & 45 & $0,01-47,21$ \\
\hline $\begin{array}{l}\text { Deetilatrazina (produto } \\
\text { degradação da atrazina) }\end{array}$ & - & $\mathrm{ND}$ & 1 & 0,02 & 22 & $0,01-13,84$ \\
\hline Deltametrina & - & ND & - & ND & - & ND \\
\hline $\begin{array}{l}\text { Diisopropilatrazina (produto } \\
\text { degradação da atrazina) }\end{array}$ & - & ND & - & ND & - & ND \\
\hline Cipermetrina & - & ND & - & ND & 5 & $0,02-0,52$ \\
\hline Clorpirifós & 4 & $0,02-0,12$ & 3 & $0,01-0,04$ & 31 & $0,01-0,88$ \\
\hline Endosulfan $\alpha$ & 9 & $0,72-0,82$ & 13 & $0,01-0,82$ & 40 & $0,01-1,15$ \\
\hline Endosulfan $\beta$ & 7 & $0,01-0,21$ & 12 & $0,02-0,26$ & 43 & $0,01-0,87$ \\
\hline Endosulfan sulfato & 5 & $0,01-0,10$ & - & ND & 40 & $0,01-0,58$ \\
\hline Flutriafol & 10 & $0,01-0,40$ & 12 & $0,03-0,34$ & 58 & $0,02-0,93$ \\
\hline Malation & 3 & $0,02-8,83$ & - & $\mathrm{ND}$ & 25 & $0,01-3,36$ \\
\hline Metilparation & - & ND & - & ND & 8 & $0,02-2,45$ \\
\hline Metolacloro & 11 & $0,01-0,24$ & 8 & $0,01-0,59$ & 43 & $0,01-2,43$ \\
\hline Monocrotofós & - & $\mathrm{ND}$ & - & ND & 29 & $0,01-41,35$ \\
\hline Permetrina & 1 & 1,40 & 1 & 0,19 & 1 & 0,13 \\
\hline Trifluralina & - & ND & - & ND & - & ND \\
\hline
\end{tabular}

ND - Não detectado; DT - Detectado, mas não quantificado

Tabela 4. Resultados das Análises de resíduos de agrotóxicos em água superficial (rios), de poços artesianos (potável) e de chuva coletadas em Campo Verde, MT entre outubro de 2007 e abril de 2009

\begin{tabular}{|c|c|c|c|c|c|c|}
\hline \multirow[b]{2}{*}{ Agrotóxicos } & \multicolumn{2}{|c|}{ Água de Poço } & \multicolumn{2}{|c|}{ Água superficial } & \multicolumn{2}{|c|}{ Água de chuva } \\
\hline & $\begin{array}{c}\text { Amostras } \\
\text { Positivas } \\
(\mathrm{N}=28)\end{array}$ & $\begin{array}{c}\text { Intervalo } \\
\text { em } \\
(\mu \mathrm{g} / \mathrm{L})\end{array}$ & $\begin{array}{c}\text { Amostras } \\
\text { Positivas } \\
(\mathrm{N}=16)\end{array}$ & $\begin{array}{c}\text { Concentração } \\
\mu \mathrm{g} / \mathrm{L}\end{array}$ & $\begin{array}{c}\text { Amostras } \\
\text { Positivas } \\
(\mathrm{N}=58)\end{array}$ & $\begin{array}{c}\text { Concentração } \\
(\mu \mathrm{g} / \mathrm{L})\end{array}$ \\
\hline Atrazina & 1 & 18,96 & 2 & $0,25-9,33$ & 31 & $0,21-75,43$ \\
\hline DEA & - & ND & 1 & DT & 3 & $1,2-4,45$ \\
\hline Deltametrina & - & ND & - & $\mathrm{ND}$ & - & ND \\
\hline DIA & - & $\mathrm{ND}$ & - & $\mathrm{ND}$ & - & ND \\
\hline Cipermetrina. & - & $\mathrm{ND}$ & - & $\mathrm{ND}$ & - & $\mathrm{ND}$ \\
\hline Clorpirifós & - & ND & - & $\mathrm{ND}$ & - & ND \\
\hline Endossulfan $\alpha$ & 3 & $0,45-0,56$ & 1 & 0,5 & 26 & DT $-11,45$ \\
\hline Endossulfan $\beta$ & 2 & $0,18-0,54$ & 1 & 0,94 & 4 & $0,27-1,51$ \\
\hline Endossulfan sulfato & - & ND & - & ND & 13 & $2,00-7,59$ \\
\hline Flutriafol & 5 & $0,23-57,11$ & - & ND & 26 & DT $-29,64$ \\
\hline Malation & - & ND & - & ND & 2 & $4,37-7,08$ \\
\hline Metiparation & - & ND & - & $\mathrm{ND}$ & 1 & 0,71 \\
\hline Metolacloro & 3 & $0,26-1,48$ & - & ND & 15 & $0,11-4,49$ \\
\hline Monocrotofós & - & ND & - & $\mathrm{ND}$ & - & ND \\
\hline Permetrina & - & ND & - & $\mathrm{ND}$ & - & ND \\
\hline Trifluralina & - & ND & - & ND & - & ND \\
\hline
\end{tabular}

$\mathrm{N}$ - número de amostras coletadas; ND - Não detectado; DT - Detectado, mas não quantificado 
$\mathrm{Na}$ maioria dos casos, os valores encontrados estão abaixo daqueles recomendados pela Resolução Conama $357^{13}$. Em uns poucos, valores muito superiores aos legais foram encontrados para os resíduos de atrazina e de endosulfan, mesmo para águas da classe 3.

Com relação às amostras de água de chuva, em Lucas do Rio Verde foi verificado que das 104 amostras coletadas entre setembro de 2007 e abril de 2009, 56\% deram positivas para pelo menos três tipos e diferentes níveis de resíduos de agrotóxicos. As concentrações de agrotóxicos, detectadas nas amostras de água pluvial, variaram de 0,01 a 47,21 $\mu \mathrm{g} / \mathrm{L}$. Resíduos de endosulfan-sulfato foram detectados em $38 \%$ das amostras, o metolacloro e o endosulfan- $\beta$ foram detectados em 56\% das amostras, a atrazina em 43\% das amostras e o flutriafol em 51\% das amostras. Todos os agrotóxicos, exceto DIA e DEA, detectados na área agrícola ou próxima dela, foram também detectados nas amostras coletadas na área urbana.

Em Campo Verde, das amostras de água de chuva coletadas (58 amostras coletadas em 4 pontos) foram detectados e quantificados resíduos de DEA (1,2 a 4,45 $\mu \mathrm{g} / \mathrm{L}$ em 3 amostras), atrazina $(0,21$ a $75,43 \mu \mathrm{g} / \mathrm{L}$ em 31 amostras), me- til paration $(0,71 \mu \mathrm{g} / \mathrm{L}$ em 1 amostra $)$, malation (4,37 e 7,08 $\mu \mathrm{g} / \mathrm{L}$ em 2 amostras), metolacloro (0,11 a $4,49 \mu \mathrm{g} / \mathrm{L}$ em 15 amostras), endosulfan alfa e beta (de 0, 5 a 29,64 $\mu \mathrm{g} / \mathrm{L}$ em 26 amostras), flutriafol (027 a 1,51 ìg/L em 4 amostras) e endosulfan $\mathrm{S}$ ( 2,0 a 7,59 $\mu \mathrm{g} / \mathrm{L}$ em 5 amostras).

\section{Resultados do estudo ecotoxicológico}

Para avaliar a possível contaminação de organismos por exposição ambiental e os eventuais impactos dos agrotóxicos na reprodução e no desenvolvimento de anfíbios, foram analisados o plasma sanguíneo quanto a presença de organoclorados em 14 indivíduos de sapo-cururu (Rhinella schneideri) e 22 indivíduos de rãpimenta (Leptodactylus labyrinthicus) em dois córregos (Cedro e Xixi) do município de Lucas do Rio Verde (Tabela 5). Foram ainda analisados resíduos de agrotóxicos no sedimento e na água do córrego do Xixi (porção represada).

Os resultados da análise dos sedimentos do córrego Xixi revelaram a presença de resíduos de endosulfan $\alpha$, $\beta$ e S $(0,38$ a $0,93 \mu \mathrm{g} / \mathrm{kg})$ e flutriafol $(0,25$ a $0,49 \mu \mathrm{g} / \mathrm{kg})$. Resíduos de atrazina $(0,18$ a $0,26 \mu \mathrm{g} / \mathrm{L})$ foram também detectados na água. Resíduos de endosulfan foram também detecta-

Tabela 5. Resultados das análises de resíduos de agrotóxicos, em ng/mL, em amostras de sangue de 36 indivíduos (anfíbios) coletados em cursos d'águas em Lucas do Rio Verde MT. Coleta realizada em fev/ 2010

\begin{tabular}{|c|c|c|c|c|}
\hline \multirow[b]{2}{*}{ Substância/agrotóxico } & \multicolumn{2}{|c|}{ Leptodactylus labyrinthicus (Rã) } & \multicolumn{2}{|c|}{ Rhinella schneideri (Sapo) } \\
\hline & $\begin{array}{c}\mathrm{N}=22 \\
\text { Amostras } \\
\text { Positivas }\end{array}$ & $\begin{array}{c}\text { Concentração } \\
\text { (ng.mL-1) }\end{array}$ & $\begin{array}{c}\mathrm{N}=14 \\
\text { Amostras } \\
\text { Positivas }\end{array}$ & $\begin{array}{c}\text { Concentração } \\
\text { (ng.mL-1) }\end{array}$ \\
\hline Tetraclorobifenila & 6 & $0,46-2,32$ & 8 & $1,54-4,65$ \\
\hline Dieldrin & 8 & $0,40-1,21$ & 7 & $0,28-1,21$ \\
\hline $\mathrm{a}-\mathrm{HCH}$ & 14 & $0,36-1,18$ & 6 & $0,26-1,14$ \\
\hline Aldrin & 1 & 1,50 & 4 & $0,30-2,91$ \\
\hline pp'-DDE & 8 & $0,47-2,67$ & 3 & $0,61-1,05$ \\
\hline Endolsulfan II & 11 & $1,45-2,78$ & 3 & $2,28-3,92$ \\
\hline Endrin & - & ND & 2 & $1,70-4,01$ \\
\hline Mirex & 11 & $0,15-6,67$ & 2 & $1,16-2,60$ \\
\hline Endosulfan-I & 6 & $0,24-1,06$ & 2 & $0,25-0,49$ \\
\hline Heptaclor Epóxido B & - & ND & 2 & $0,21-0,50$ \\
\hline a-Clordano & 1 & 0,30 & 1 & 1,43 \\
\hline t-Nonaclor & 1 & 0,52 & 1 & 1,03 \\
\hline pp'-DDT & 3 & $1,3-2,75$ & 1 & 1,60 \\
\hline$o, p^{\prime}-\mathrm{DDD}$ & 3 & $0,44-0,65$ & - & $\mathrm{ND}$ \\
\hline $\mathrm{b}-\mathrm{HCH}$ & 3 & $0,29-0,78$ & - & $\mathrm{ND}$ \\
\hline Pentacloroanisol & 1 & 0,28 & - & $\mathrm{ND}$ \\
\hline Dicofol & 1 & 1,80 & - & $\mathrm{ND}$ \\
\hline Heptaclor epoxido A & 1 & 0,59 & - & ND \\
\hline
\end{tabular}

ND - não detectado 
dos por cromatografia gasosa no plasma sanguíneo de sete sapos (35\% da amostra analisada, com valores de 0,25 a $3,92 \mathrm{ng} / \mathrm{ml})$ e 11 rãs $(50 \%$ da amostra analisada, com valores de 0,24 a 1,06 $\mathrm{ng} / \mathrm{ml})$. Sabe-se que tanto o endosulfan quanto a atrazina tem propriedades teratogênicas.

De fato, após a coleta dos animais e o transporte para o laboratório, foram detectadas malformações apendiculares (ectromelia, ou ausência congênita ou desenvolvimento incompleto dos ossos longos de um ou mais membros locomotores; sindactilia, ou fusão das falanges dos membros anteriores; e cruzamento do $4^{\circ}$ dedo sobre o $3^{\circ}$ dedo do membro anterior esquerdo sensu Meteyer ${ }^{14}$ ) em 10\% dos sapos-cururu coletados (cinco indivíduos). Essas anomalias foram registradas tanto por exame visual externo como por comprovação radiológica, segundo metodologia validada por Rodrigues et al. ${ }^{15}$. Nenhuma rã-pimenta apresentou malformações apendiculares.

\section{Discussão}

A análise dos resultados do estudo mostrou que os agrotóxicos utilizados nas atividades agrícolas dos municípios de Lucas do Rio Verde e Campo Verde, no estado do Mato Grosso, estão afetando o ambiente das áreas do entorno e próximas às zonas de plantio, nomeadamente as águas superficiais (incluindo as de consumo humano) e a água das chuvas. Mesmo nos centros urbanos desses municípios foi possível detectar resíduos de agrotóxicos usados na produção agrícola em amostras de águas de poços artesianos, rios, córregos e água de chuva.

Um primeiro aspecto a ser destacado é a concentração em que tais agentes químicos foram detectados nas amostras de água superficial. Mesmo que a maioria das amostras coletadas tenham apresentado concentrações abaixo dos limites estabelecidos pela legislação brasileira vigente, não se pode excluir a possibilidade de que algumas destas substâncias, principalmente aquelas com capacidade de serem bioacumuladas ou as com propriedades mutagênicas e teratogênicas, possam estar causando impacto sobre a qualidade do ambiente, da biota local e, em último caso, a saúde humana. Ademais, cabe ressaltar que existem outras legislações em vigor muito mais restritivas que a brasileira, como é o caso da União Europeia.

A legislação da União Europeia ${ }^{16}$ é mais restritiva e estabelece como valor paramétrico para resíduos de agrotóxicos em água potável para "cada agrotóxico isoladamente" (que não sejam o aldrin, o dieldrin, o heptacloro e o heptacloro epóxido, para os quais o valor estabelecido é de $1 \mu \mathrm{g} / \mathrm{L}$ para o somatório de todos os seus resíduos), o valor de $0,5 \mu \mathrm{g} / \mathrm{l}$. Com base nesta legislação, teríamos, especialmente em Campo Verde, mais amostras com concentrações superiores ao limite, ou seja, impróprias para o consumo.

Ademais, mesmo nos casos em que os valores estejam abaixo dos limites legais, deve-se considerar a capacidade de bioacumulação nos tecidos gordurosos dos organismos de algumas substâncias e também os efeitos sinérgicos ou antagônicos que podem acontecer em casos de exposição a múltiplos resíduos o que torna o problema mais complexo e bem menos conhecido. Soma-se a isto o fato de que muito pouco se conhece sobre os possíveis efeitos tardios que uma exposição múltipla e continuada a baixas doses de agrotóxicos possa trazer à saúde destas populações, especialmente das mais vulneráveis.

Entre os agrotóxicos identificados nas amostras coletadas, cabe destaque, aqui, ao endosulfan (alfa e beta) que, em algumas coletas, foi detectado em concentrações que superaram os valores legais estabelecidos no país. O uso agrícola do endosulfan está atualmente banido em mais de 62 países do mundo enquanto em outros encontra-se em fase de banimento. Em 2010, a Agência de Proteção Ambiental dos Estados Unidos (EPA) decidiu banir o uso de endosulfan nos EUA devido a trazer um risco inaceitável para os trabalhadores, para a vida aquática e terrestre bem com para pássaros e mamíferos que consomem organismos aquáticos onde o endosulfan pode ter sido bioacumulado e também devido à sua persistência ambiental ${ }^{17}$.

Atualmente, existe, no país, uma grande mobilização em torno da possível proibição do inseticida endosulfan, um dos 14 agrotóxicos atualmente em reavaliação pela Anvisa ${ }^{18}$. Diversos problemas de saúde vêm sendo relacionados nas últimas duas décadas, na literatura científica internacional, à exposição ao endosulfan, entre esses distúrbios do sistema nervoso central ${ }^{19}$, doenças hepáticas, renais e cardiorrespiratórias ${ }^{20}$, entre outras manifestações de exposição crônica a esses agentes químicos.

Outro dado que cabe destaque é o registro, nos municípios de Lucas do Rio Verde e Campo Verde, da diminuição do uso de agrotóxicos de classes mais tóxicas e o aumento do uso de princípios ativos menos tóxicos, em particular da classe IV (pouco tóxica), na qual se encontra o glifo- 
sato, principal agrotóxico associado à cultura de cana. Embora estes resultados possam, à primeira vista, parecerem alentadores, a relação entre a classificação toxicológica e os efeitos ecotoxicológicos não é linear. De fato, vários trabalhos têm demonstrado impactos sobre a biota resultantes da exposição crônica mesmo a agrotóxicos classificados como pouco tóxicos. Por exemplo, estudos têm demonstrado efeitos negativos do glifosato sobre a morfologia normal e a reprodução de minhocas expostas a este agrotóxico por períodos de até 60 dias, embora nenhuma morte tenha sido observada durante o experimento ${ }^{21}$.

Diversos outros estudos, de base experimental $^{22-25}$, clínica ${ }^{26,27}$ e epidemiológica ${ }^{28,29}$ vêm apontando o glifosato como potencial disruptor endócrino. Outros problemas de saúde também associados à exposição a glifosato incluem rinite ${ }^{30}$, alterações no DNA/mutagêneses ${ }^{31}$ e dermatites ${ }^{32}$.

O glifosato é um herbicida de baixa toxicidade aguda, amplamente utilizado no controle de pragas vegetais, principalmente nas culturas de soja geneticamente modificadas. Em razão desse elevado consumo, associado às suspeitas sobre o seu potencial interferente no sistema endócrino humano, o glifosato também foi incluído na lista dos 14 agrotóxicos atualmente em reavaliação pela Anvisa ${ }^{18}$.

A detecção de resíduos de agrotóxicos em mais da metade das amostras de águas de chuva coletadas nas duas cidades evidencia uma importante via de contaminação ambiental, caracterizada pela volatilização dos agrotóxicos utilizados no meio rural, sua acumulação em formações plúmbeas, transporte pelo vento e, por fim, precipitação. Os dados obtidos ao longo do presente estudo refletem não apenas a deposição úmida dos agrotóxicos volatilizados na atmosfera, como também o transporte desde as áreas de cultivo até as áreas urbanas e áreas não cultivadas. Tal fato é particularmente importante quando consideramos que, nessa região, situam-se três dos mais importantes biomas brasileiros: o Pantanal; a Floresta Amazônica; e o Cerrado, que podem estar recebendo estes resíduos carreados pelos ventos e pelas chuvas.

Ainda em relação à análise de resíduos de agrotóxicos em água de chuva, existem poucos estudos sobre o tema na literatura internacional. Dentre esses podemos destacar os estudos de $\mathrm{He}$ e Balasubramanian ${ }^{33}$, que analisaram resíduos de compostos semivoláteis (incluindo um agrotóxico, o PCB) em amostras de água de chuva coletadas em área urbana (Singapura), Schummer et al. ${ }^{34}$, que analisaram a presença de agrotó- xicos à base de fenóis e nitrofenóis em amostras de água de chuva de regiões rurais e urbana da França, Trajkovska et al. ${ }^{35}$, que analisaram resíduos de agrotóxicos em amostras de água de chuva coletadas em Paris, Peters et al. ${ }^{36}$, que identificaram agrotóxicos (entre outros xenobióticos) em amostras de águas de chuva coletadas em 50 pontos ao redor da Holanda e de Malik et al. ${ }^{37}$, que observaram a ocorrência de traços de agrotóxicos usados na agricultura em amostras de água de chuva coletadas em área urbana na Índia.

Um fato registrado em todos os supracitados estudos, assim como no presente trabalho, foi a capacidade de dispersão de agrotóxicos utilizados no meio rural, principalmente os mais persistentes, para os centros urbanos através da água de chuvas, o que representa uma importante e pouco estudada via de contaminação ambiental. Como não há limites de segurança para a presença de resíduos de agrotóxicos em água de chuva, é impossível dimensionar o real impacto de tal via na deterioração da qualidade do ambiente, da saúde humana e da biodiversidade.

Outro fato observado, e de particular importância para a região Centro-Oeste brasileira, é a expressão maior dessa via de contaminação ambiental em áreas mais quentes e úmidas ${ }^{33,37}$, o que coloca grande parte da região Centro-Oeste - em particular aquelas áreas adjacentes aos biomas do Pantanal e da Floresta Amazônica numa condição de vulnerabilidade face à possibilidade de ocorrência de resíduos de agrotóxicos em chuvas.

Um dos agrotóxicos mais detectados nas amostras de água de chuvas coletadas foi a atrazina. Tal é a preocupação acerca dos possíveis efeitos negativos desses resíduos de atrazina em água de chuva que a EPA, em um documento consolidado sobre a regulação ambiental do uso de atrazina nos EUA, recomenda a suspensão do uso desse herbicida quando há indicação (previsão) de chuvas $^{38}$.

No mesmo documento ${ }^{38}$, essa Agência aponta a necessidade do monitoramento da qualidade de cursos d'água em áreas onde há o uso de atrazina, incluindo estudos ecotoxicológicos para a detecção de possíveis efeitos negativos sobre determinadas espécies, em particular anuros. A literatura científica registra que malformações em anfíbios podem ocorrer por vários fatores ambientais, incluindo radiação ultravioleta ${ }^{39}$, ação de parasitos ${ }^{39,40}$ e exposição a agrotóxicos ${ }^{41-43}$.

Os resultados ecotoxicológicos obtidos, em nosso estudo, através do exame do plasma sanguíneo revelaram resíduos de endosulfan e ou- 
tros agrotóxicos organoclorados nestes animais que reconhecidamente apresentam propriedades teratogênicas. Estudo sobre a carga parasitária destes animais está em andamento e somente com estes resultados que uma avaliação se a ação conjunta e/ou isolada de agrotóxicos e parasitas tem provocado as malformações nos sapos-cururu.

Apesar da necessidade de análises adicionais, os resultados indicam que indivíduos de duas espécies de anuros coletados em lagos e córregos próximos às plantações sofreram alterações morfofisiológicas consistentes com casos documentados na literatura internacional acerca dos efeitos nocivos da contaminação ambiental por atrazina em espécies bioindicadoras de ambientes aquáticos, em particular anuros ${ }^{41,44-46}$.

Outros agrotóxicos largamente utilizados nos processos agrícolas de Lucas do Rio Verde e Campo Verde, como o herbicida glifosato ${ }^{47-49}$ e os inseticidas malation ${ }^{43}$, carbaril $^{50}$ e cipermetrina ${ }^{42}$, também vêm sendo associados, em estudos ecotoxicológicos, a diferentes anormalidades morfofisiológicas encontradas em anuros coletados em áreas próximas a produções agrícolas. Além dos efeitos diretos da contaminação ambiental por agrotóxicos sobre esses animais (efeitos estes que variam desde a perda da capacidade natatória de larvas até a mudanças de sexo em indivíduos adultos, passando por diversas alterações morfológicas), também é possível considerar os impactos indiretos dessa poluição ambiental, uma vez que muitas espécies de anuros afetadas por agrotóxicos atuam como controladoras de populações de insetos, alguns dos quais de importante interesse para a produção agrícola (pragas) e outros potenciais vetores de doenças.

\section{Conclusões}

Este estudo mostra que a agricultura dos municípios estudados está impactando os recursos hídricos regionais e repercutindo sobre a biota. Esta situação tende a se agravar com a ampliação esperada da produtividade e da área cultivada em grande parte do estado do Mato Grosso.

A contaminação das águas de córregos e da água de chuvas indica uma contaminação atmosférica que afeta áreas não cultivadas, como os centros urbanos, tornando a extensão de possíveis impactos ou riscos sobre a saúde ambiental de difícil mensuração. Os resultados apontam, ainda, para a deterioração da água potável que, em algumas amostras, continha resíduos de agro- tóxicos em concentrações superiores àquelas recomendadas pela UE.

Alguns impactos sobre a biota (anfíbios) que foram detectados podem estar associados a esta exposição. A elevada incidência de malformação já observada nos sapos-cururu pode ser ainda mais elevada, fato este que pode ser confirmado com análises complementares como a carga parasitária, a presença de micronúcleos, o DNA, a ectoscopia interna e a análise histológica de órgãos/tecidos.

Por fim, cabe considerar que uma parte significativa das áreas de produção agrícola do estado do Mato Grosso (e de outros estados da Região Centro-Oeste) fica próxima a áreas de preservação ambiental de três importantes (e endêmicos) biomas brasileiros: o Cerrado, o Pantanal e a Floresta Amazônica. Através da via de contaminação ambiental observada no presente estudo, representada pela volatilização de agrotóxicos usados nos processos agrícolas e sua precipitação através das chuvas, é possível considerar a existência de impactos (de difícil mensuração) do uso de agrotóxicos na região sobre a saúde ambiental bem como sobre a qualidade dos cursos d'água presentes nessas áreas de preservação.

Os dados aqui apresentados e discutidos expõem, claramente, a necessidade de novos estudos, especialmente aqueles de monitoramento de longa duração, para que possam ser solidamente avaliados os riscos bem como realizado o acompanhamento de eventuais efeitos agudos e crônicos desta exposição a múltiplos resíduos de agrotóxicos sobre as populações residentes e sobre a biota, estratégias de vigilância em saúde ambiental naquele e em outros estados brasileiros.

\section{Colaboradores}

JC Moreira, F Peres, AC Simões, WA Pignati, EC Dores, SN Vieira, C Strüssmann e T Mott participaram igualmente de todas as etapas de elaboração do artigo.

\section{Agradecimentos}

Os autores gostariam de agradecer ao CNPq pelo apoio financeiro. F Peres é bolsista da CAPES de Estágio Pós-doutoral no Exterior. 
2. Ministério da Agricultura, Pecuária e Abastecimento (MAPA). Projeções do Agronegócio: Brasil 2009/ 2010 a 2019/2020. Brasília: MAPA; 2010. [acessado 2012 fev 1]. Disponível em: http://www.agricultura. gov.br/arq_editor/file/Ministerio/planos $\% 20 \mathrm{e} \% 20$ programas/projecoes_web1.pdf

3. Companhia Nacional de Abastecimento (Conab). Acompanhamento da Safra Brasileira - 9o Levantamento (Grãos), Junho de 2011. Brasília: Conab; 2011. [acessado 2012 fev 1]. Disponível em: http:// www.conab.gov.br/OlalaCMS/uploads/arquivos/ 11_07_04_14_46_46_graos_-_boletim_junho-2011. pdf

4. Instituto de Desenvolvimento Agropecuário do Mato Grosso (Indea). Planilha de Dados do Sistema de Informação de Agrotóxicos (CD). anos 2005 a 2007. Cuiabá: Instituto de Desenvolvimento Agropecuário do Mato Grosso; 2008. (banco de dados eletrônico)

5. Instituto de Desenvolvimento Agropecuário do Mato Grosso (Indea). Planilha de Dados do Sistema de Informação de Agrotóxicos (CD). anos 2008 a 2009. Cuiabá: Instituto de Desenvolvimento Agropecuário do Mato Grosso; 2010. (banco de dados eletrônico)

6. Agência Nacional de Vigilância Sanitária (Anvisa). RDC 01 de 17 de janeiro de 2011. Brasília: Anvisa 2011.

7. Agência Nacional de Vigilância Sanitária (Anvisa). RDC 28 de 16 de agosto de 2010. Brasília: Anvisa; 2010.

8. Mato Grosso. Secretaria de Planejamento (SEPLAN). Anuário Estatístico 2004. Cuiabá: Secretaria de Planejamento do Mato Grosso; 2004. [acessado 2012 fev 1]. Disponível em: http://www.seplan. mt.gov.br/anuario2004/2.19.htm

9. Prefeitura Municipal de Lucas do Rio Verde. Portal da PMLRV - Economia. Lucas do Rio Verde: Prefeitura Municipal de Lucas do Rio Verde; 2011. [acessado 2012 fev 1]. Disponível em: http://www. lucasdorioverde.mt.gov.br/economia.asp

10. Prefeitura Municipal de Campo Verde. Portal da $P M C V$ - Economia. Campo Verde: Prefeitura Municipal de Campo Verde; 2011. [acessado $2012 \mathrm{fev}$ 1]. Disponível em: http://www.campoverde.mt. gov.br/interna/informacoes/economia.html

11. Santos LG, Lourencetti C, Pinto AA, Pignati WA, Dores EFGC. Validation and application of an analytical method for determining pesticides in the gas phase of ambient air. Environ. Sci. Health. Part B 2001; 46(2):150-162.

12. Brasil. Ministério da Saúde. Portaria MS 2.914 de 4 de dezembro de 2011. Brasília: Ministério da Saúde; 2001. [acessado $2012 \mathrm{fev} \mathrm{1]}$. Disponível em: http: / /www.comitepcj.sp.gov.br/download/Portaria_ MS_2914-11.pdf

13. Brasil. Ministério do Meio Ambiente. Conselho Nacional do Meio Ambiente (Conama). Resolução 357 de 17 de março de 2005. Brasília: Conama; 2005. [acessado 2012 fev 1]. Disponível em: http://www. mma.gov.br/port/conama/res/res05/res35705.pdf

14. Meteyer CU. Field guide to malformations of frogs and toads with radiographics interpretations. Biological Science Report. USGS/BRD/BSR-2000-0005. Madison: United States Geological Survey/U.S. Dept. of Interior; 2000. [acessado $2012 \mathrm{fev} \mathrm{1]}$. Disponível em: http://www.nwhc.usgs.gov/publications/fact_sheets/ pdfs/frog.pdf

15. Rodrigues TFD, Mott T, Strüssmann C, Barbosa LM, Grizante MB, Singarette ME, Kohlsdorf T. Malformações em Rhinella schneideri (Amphibia, Anura, Bufonidae) no município de Lucas do Rio Verde, Mato Grosso, Brasil. [Pôster]. Pirinópolis: IV Congresso Brasileiro de Herpetologia; 2009.

16. União Europeia. Diretiva 98/83/CE do Conselho da União Europeia de 5/12/1998 Relativa à Qualidade da Água Para Consumo Humano. Bruxelas: União Europeia; 1998. [acessado $2012 \mathrm{fev} 1$ 1]. Disponível em: http://eur-lex.europa.eu/LexUriServ/LexUriServ.do ?uri=OJ:L:1998:330:0032:0054:PT:PDF

17. United States Environmental Protection Agency (EPA). Pesticides: Regulation: Endosulfan Phase-Out. Washington DC: United States Environmental Protection Agency; 2010. [acessado $2012 \mathrm{fev} 1$ ]. Disponível em: http:/ /www.epa.gov/pesticides/reregistration/endosulfan/ endosulfan-agreement.html\#background

18. Agência Nacional de Vigilância Sanitária (Anvisa). RDC 10 de 07 de julho de 2008. Brasília: Anvisa; 2008.

19. Moon JM, Chun BJ. Acute endosulfan poisoning: a retrospective study. Hum Exp Toxicol. 2009; 28(5): 309-316.

20. Eyer F, Felgenhauer N, Jetzinger E, Pfab R, Zilker TR. Acute endosulfan poisoning with cerebral edema and cardiac failure. J Toxicol Clin Toxicol. 2004; 42(6):927-932.

21. Correia FV, Moreira JC. Effects of glyphosate and 2,4D on earthworms (Eisenia foetida) in laboratory tests. Bull Environ Contam Toxicol. 2010; 85(3):264-268.

22. Brake DG, Everson DP. A generational study of glyphosate-tolerant soybeans on mouse fetal, postnatal, pubertal and adult testicular development. Food Chem Toxicol 2004; 42(1):29-36.

23. Dallegrave E, Mantese FD, Coelho RS, Pereira JD, Dalsenter PR, Langeloh A. The teratogenic potential of the herbicide glyphosate-Roundup in Wistar rats. Toxicol Lett. 2003; 142(1-2):45-52.

24. Gasnier C, Dumont C, Benachour N, Clair E, Chagnon MC, Séralini GE. Glyphosate-based herbicides are toxic and endocrine disruptors in human cell lines. Toxicology. 2009; 262(3):184-191.

25. Hokanson R, Fudge R, Chowdhary R, Busbee D. Alteration of estrogen-regulated gene expression in human cells induced by the agricultural and horticultural herbicide glyphosate. Hum Exp Toxicol. 2007; 26(9):747-752. 
26. Benachour N, Sipahutar H, Moslemi S, Gasnier C, Travert C, Séralini GE. Time- and dose-dependent effects of roundup on human embryonic and placental cells. Arch Environ Contam Toxicol. 2007; 53(1): 126-133.

27. Romano RM, Romano MA, Bernardi MM, Furtado PV, Oliveira CA. Prepubertal exposure to commercial formulation of the herbicide glyphosate alters testosterone levels and testicular morphology. Arch Toxicol. 2010; 84(4):309-317.

28. Curwin B, Sanderson W, Reynolds S, Hein M, Alavanja $M$. Pesticide use and practices in an Iowa farm family pesticide exposure study. J Agric Saf Health. 2002; 8(4):423-433.

29. Solomon KR, Marshall EJ, Carrasquilla G. Human health and environmental risks from the use of glyphosate formulations to control the production of coca in Colombia: overview and conclusions. $J$ Toxicol Environ Health A, 2009; 72(15-16):914-920.

30. Slager RE, Simpson SL, Levan TD, Poole JA, Sandler DP, Hoppin JA. Rhinitis associated with pesticide use among private pesticide applicators in the agricultural health study. J Toxicol Environ Health A 2010; 73(20):1382-1393.

31. Mladinic M, Berend S, Vrdoljak AL, Kopjar N, Radic B, Zeljezic D. Evaluation of genome damage and its relation to oxidative stress induced by glyphosate in human lymphocytes in vitro. Environ $\mathrm{Mol}$ Mutagen. 2009; 50(9):800-807.

32. Nielsen JB, Nielsen F, Sorensen JA. Defense against dermal exposures is only skin deep: significantly increased penetration through slightly damaged skin. Arch Dermatol Res. 2007; 299(9):423-431.

33. He J, Balasubramanian R. Semi-volatile organic compounds (SVOCs) in ambient air and rainwater in a tropical environment: concentrations and temporal and seasonal trends. Chemosphere 2010; 78(6): 742-751.

34. Schummer C, Groff C, Al Chami J, Jaber F, Millet $\mathrm{M}$. Analysis of phenols and nitrophenols in rainwater collected simultaneously on an urban and rural site in east of France. Sci Total Environ. 2009; 407(21):5637-5643.

35. Trajkovska S, Mbaye M, Gaye-Seye MD, Aaron JJ, Chevreuil M, Blanchoud H. Toxicological study of pesticides in air and precipitations of Paris by means of a bioluminescence method. Anal Bioanal Chem. 2009; 394(4):1099-1106.

36. Peters RJ, Beeltje H, Van Delft RJ. Xeno-estrogenic compounds in precipitation. J Environ Monit. 2008; 10(6):760-769.

37. Malik A, Singh VK, Singh KP. Occurrence and distribution of persistent trace organics in rainwater in an urban region (India). Bull Environ Contam Toxicol. 2007; 79(6):639-645.

38. United States Environmental Protection Agency (EPA). Decision Documents for Atrazine. Washington DC: EPA; 2006. [acessado 2012 jan 9]. Disponível em: http://www.epa.gov/oppsrrd1/REDs/atrazine_ combined_docs.pdf

39. Ankley GT, Degitz SJ, Diamond SA, Tietge JE. Assessment of environmental stressors potentially responsible for malformations in North American anuran amphibians. Ecotoxicol Environ Saf. 2004; 58(1):7-16.
40. Romansic JM, Johnson PT, Searle CL, Johnson JE, Tunstall TS, Han BA, Rohr JR, Blaustein AR. Individual and combined effects of multiple pathogens on Pacific treefrogs. Oecologia. 2011; 166(4):1029-1041.

41. Brodeur JC, Svartz G, Perez-Coll CS, Marino DJ, Herkovits J. Comparative susceptibility to atrazine of three developmental stages of Rhinella arenarum and influence on metamorphosis: non-monotonous acceleration of the time to climax and delayed tail resorption. Aquat Toxicol. 2009; 91(2):161-170.

42. Agostini MG, Natale GS, Ronco AE. Lethal and sublethal effects of cypermethrin to Hypsiboas pulchellus tadpoles. Ecotoxicology 2010; 19(8):1545-1550.

43. Krishnamurthy SV, Smith GR. Combined effects of malathion and nitrate on early growth, abnormalities, and mortality of wood frog (Rana sylvatica) tadpoles. Ecotoxicology 2011; 20(6):1361-1367.

44. Mcdaniel TV, Martin PA, Struger J, Sherry J, Marvin $\mathrm{CH}$, McMaster ME, Clarence S, Tetreault G. Potential endocrine disruption of sexual development in free ranging male northern leopard frogs (Rana pipiens) and green frogs (Rana clamitans) from areas of intensive row crop agriculture. Aquat Toxicol. 2008; 88(4):230-242.

45. Spolyarich N, Hyne RV, Wilson SP, Palmer CG, Byrne M. Morphological abnormalities in frogs from a rice-growing region in NSW, Australia, with investigations into pesticide exposure. Environ Monit Assess. 2011; 173(1-4):397-407.

46. Zaya RM, Amini Z, Whitaker AS, Kohler SL, Ide CF. Atrazine exposure affects growth, body condition and liver health in Xenopus laevis tadpoles. Aquat Toxicol. 2011; 104(3-4):243-253.

47. Edge CB, Gahl MK, Pauli BD, Thompson DG, Houlahan JE. Exposure of juvenile green frogs (Lithobates clamitans) in littoral enclosures to a glyphosate-based herbicide. Ecotoxicol Environ Saf. 2011; 74(5):1363-1369.

48. Gahl MK, Pauli BD, Houlahan JE. Effects of chytrid fungus and a glyphosate-based herbicide on survival and growth of wood frogs (Lithobates sylvaticus). Ecol Appl. 2011; 21(7):2521-2529.

49. Lajmanovich RC, Attademo AM, Peltzer PM, Junges CM, Cabagna MC. Toxicity of four herbicide formulations with glyphosate on Rhinella arenarum (anura: bufonidae) tadpoles: B-esterases and glutathione S-transferase inhibitors. Arch Environ Contam Toxicol. 2011; 60(4):681-689.

50. Bulen BJ, Distel CA. Carbaryl concentration gradients in realistic environments and their influence on our understanding of the tadpole food web. Arch Environ Contam Toxicol. 2011; 60(2):343-350.

Artigo apresentado em 17/04/2012

Aprovado em 19/04/2012

Versão final apresentada em 24/04/2012 